NASA Technical Memorandum 104460

\title{
Small Stirling Dynamic Isotope Power System for Multihundred-Watt Robotic Missions
}

David J. Bents

Lewis Research Center

Cleveland, Ohio

Prepared for the

International Pacific Air and Space Technology Conference sponsored by the Society of Automotive Engineers, Inc.

Gifu City, Japan, October 7-11, 1991 


\title{
Small Stirling Dynamic Isotope Power System for Multihundred-Watt Robotic Missions
}

\author{
David J. Bents \\ Lewis Research Center \\ Cleveland, Ohio
}

\section{ABSTRACT}

Free-piston Stirling engine (FPSE) and linear alternator (LA) technology is combined with radioisotope heat sources to produce a compact dynamic isotope power system (DIPS) suitable for.multihundred-watt space applications which appears competitive with advanced radioisotope thermoelectric generators (RTGs).

Unlike earlier DIPS concepts based on closed cycle Brayton conversion, the small Stirling DIPS is scaleable to multihundred-watt power levels or lower. The FPSE/LA convertor, which is not subject to the tip clearance to swept area scaling limitation of turbomachinery, remains a high efficiency convertor in sizes ranging from tens of kilowatts down to only a few watts. At multihundred-watt unit size, the FPSE can be directly integrated with the government-furnished General Purpose Heat Source (GPHS) via radiative coupling; the resulting dynamic isotope power system has a size and weight that compares favorably with the advanced modular (Mod) RTG, but requires less than a third the amount of isotope fuel. Thus the FPSE extends the high efficiency advantage of dynamic systems into a power range never previously considered competitive for DIPS. This results in lower fuel cost and reduced radiological hazard per delivered electrical watt.

Having sucessfully flown on several earlier space missions, free-piston Stirling technology

*Numbers in parentheses designate references at end of paper. has the potential to achieve, as an isotope engine, the high reliability that is required for years of unattended remote operation. Hermetically sealed inside a container, there are typically only two moving parts and no sliding seals of any kind. Incorporating noncontacting gas bearings or flexures, there is no wear between the moving parts. Terrestrially, Stirling engine convertors have demonstrated virtually unlimited service life -in test, one radioisotope heated unit has achieved over $110000 \mathrm{hr}$ continuous operation.

On Mars the small Stirling DIPS offers the benefit of being able to operate exposed to the atmosphere without degradation. RTG's must be hermetically sealed inside a container to survive.

For these reasons the small Stirling DIPS appears an economical alternative to RTG's. When it is developed, it should prove to be a strong candidate to power the many multihundred-watt robotic missions anticipated within the next three decades for deep space and planet surface exploration.

\section{INTRODUCTION}

Nuclear power sources will be needed for many of the civil space missions anticipated within the next two or three decades. These include all the deep space and outer planet missions presently in the OSSA strategic plan or proposed by the solar system exploration and space physics subcommittees (1)*, and many robotic planetary surface missions considered as precursors to later human 
exploration. These particular missions (summarized in Table 1) require multihundredwatt power sources. Although there is an eventual requirement for multikilo-watt nuclear power sources to support manned missions (construction and operation of a lunar base, for example) these manned missions probably will not take place until most of the unmanned missions have been completed. The dates listed for these missions are only estimates; most of them will not take place for ten years or more. From the known characterizations of these missions and the capabilities of the vehicles and spacecraft involved, none will require more than $700 \mathrm{~W}$. All are remote missions, in locations ranging from the lunar surface to deep space. High performance and minimum weight are desirable, but the key requirement is for reliable operation in a harsh environment, without intervention, over extended periods of time.

\section{RTGS}

The only power source presently available to meet these requirements is the radioisotope thermoelectric generator (RTG) developed for NASA by the Department of Energy (DoE). The RTG is built around the space-qualified General Purpose Heat Source (GPHS), which is also furnished by DoE. Basically an array of radiatively coupled thermoelectric (TE) cells enclosing a stack of GPHS blocks as shown in Fig. 1, this power source is the result of years of evolutionary development and flight experience. The GPHS RTGs powering the Galileo and Ulysses missions draw their design heritage and $1300 \mathrm{~K} \mathrm{Si} \mathrm{Ge} \mathrm{unicouple} \mathrm{technology}$ from their predecessors, the MHW RTGs used on Pioneer and Voyager. These units are still operating after being launched more than a decade ago. Scheduled for service on the Cassini and CRAF missions, GPHS RTG will be superceded for the later missions (Solar Probe, Pluto flyby, Comet Nucleus Sample Return etc.) by Mod RTG (2), which is the next generation in the evolutionary chain. This unit employs the new $1300 \mathrm{~K} \mathrm{Si} / \mathrm{Ge} / \mathrm{GaP}$ multicouple, which produces higher output voltage and allows modularity and improved packaging.
The RTG has demonstrated reliability wellsuited for these missions. Its thermoelectric conversion system, which has no moving parts to break or wear out, is made up of multiple series-parallel strings of redundant elements which accommodate failure of any element in the string with only partial degradation. No open circuit failures have ever been recorded; counting all the RTG powered missions flown to date, over 70 years of successful flight experience have been accumulated. For the converter, it translates to 442 million unicouple operating hours, demonstrating a reliablity in service "measured in decades" (3).

For missions where life and reliability are needed most, the RTG has proven to be a long lived and most reliable power source. But there is a high price to be paid. Since its thermoelectric conversion is not very efficient (typically 6 to 7 percent), an RTG needs a substantial amount of heat source in order to produce a few electrical watts. For example, a GPHS RTG producing 285 electrical watts at beginning of life (BOL) requires over 4.4 thermal kilowatts heat source. To the power system, this input must ultimately be disposed of as waste heat. Waste heat is a burden on the user since it must be continuously removed, placing a substantial auxilary cooling requirement on the spacecraft during launch and transit.

The heat source is expensive. The low emission spectrum and long half-life plutonium isotope used in GPHS costs roughly $\$ 1200$ a gram from the producer (4). Each GPHS is loaded with $448 \mathrm{~g}$ of active material. Counting the costs of production, encapsulation and assembly into heat source modules, the resulting mission user cost is about $\$ 6000$ per thermal watt. For an RTG, this translates to roughly $\$ 100000$ per electrical watt.

The radioisotope inventory carried by RTGs ( 460 C: per electrical watt) translates to significant safety concerns since the amount of isotope launched aboard a spacecraft determines the "source term" generated in the event of an accident $(5,6)$. To a first approximation, the numerically calculated risk versus on-board inventory is a linear relationship (i.e., the more isotope carried, the greater the risk). These risks have been considered acceptable for the 
radioisotope powered missions carried out to date but the desire to reduce or eliminate that risk has been widely recognized (7).

\section{DYNAMIC ISOTOPE POWER SYSTEMS}

Where no alternatives to isotope sources are available there is a strong incentive to at least reduce the amount of isotope that is required. This can be accomplished by developing a power source with more efficient conversion. At present, the most efficient converters of thermal energy are dynamic heat engines. When energized by an isotope heat source, the resulting power plant is known as a dynamic isotope power system, or DIPS. DIPS require less isotope per delivered electrical watt because heat engines are 3 to 5 times more efficient than thermoelectric convertors. On the other hand, they introduce the complication of moving parts.

Because they have the potential to significantly reduce the isotope inventory required for power generation, DIPS have been studied extensively for the last 25 years, and are still under consideration.

Technology programs to date have been confined to design studies and component development. During the course of earlier programs in the 1960s and early 70's, three prototype convertor loops based on turbomachinery were built and tested. These were carried to test cell demonstrations but no further because the multikilo-watt missions they were intended for never materialized.

Primary focus for convertor development has been the closed Brayton cycle. It is mechanically the most simple; the turbine, alternator and compressor assemblies can be integrated to just one rotating part which, supported on the hydrodynamic gas bearings developed in that program, does not touch anything while spinning. Considered to have high potential reliability for space power, turbomachinery demonstrates significant advantages of scaling to multi-kilowatt power levels and above, but because of the fixed losses associated with bearings and turbine tip clearances, turbomachinery does not scale very well to lower power levels (8). Generally speaking, turbomachine unit sizes below $500 \mathrm{~W}$ are considered impractical because of the fixed loss effect on overall convertor efficiency (Fig. 2).

The smallest Brayton convertor ever developed for space was the "mini-BRU" BIPS (Brayton Isotope Power System) unit built in the late 70's under NASA and DoE sponsorship at the Garrett AirResearch Co. (9). It featured a minature turboalternator compressor which was designed as a nominally $1.3 \mathrm{kWe}$ unit, but could cover the range 0.5 to $2.1 \mathrm{kWe}$ by being combined with variously sized heat source, recuperator and radiator units (Fig. 3 ). Hardware developed and tested during this program included the mini-BRU, a heat source assembly (containing the same MHW isotope heat source used to energize the Voyager RTG) and its heat exchangers, a recuperator assembly, waste heat exchangers, and multifoil insulation. This hardware was later integrated into a complete "workhorse" convertor loop and tested in vacuum using simulated (electrically heated) MHW heat sources. A convertor efficiency of 24.5 percent was measured.

Recent design studies based on this technology include the (1 to $10 \mathrm{kWe}$ ) DIPS TECS for the military Boost Surveillance and Tracking (BSTS) satellite $(10,11)$, and a scaleddown version of this system, the Low Power DIPS (12) which has also been proposed as a replacement for RTG units on interplanetary missions ( 0.25 to $1.5 \mathrm{kWe})$. Comparisons made by the developer showed that DIPS TECS would be heavier than Mod RTGs if the power requirement for BSTS was below $2 \mathrm{kWe}$. Similar comparisons for Low Power DIPS, a direct multihundred-watt application in this instance, indicated a heavier system than Mod RTG below $1 \mathrm{kWe}$, and heavier than the present GPHS RTG's at power levels below $650 \mathrm{We}$ (Fig. 4). Although the isotope savings was better than 60 percent in all cases, the weight disadvantage was substantial. The implication is that a power requirement of only a few hundred watts, together with the necessity of employing multiple redundant convertor units to ensure overall system reliability, will render a turbomachinery based DIPS to be significantly larger and heavier than an equivalent ensemble of RTG units. 


\section{SMALL STIRLING DIPS}

To produce a DIPS that is competitive with RTGs for multihundred-watt missions, the Stirling engine may be a better convertor choice. Combining isotope heat sources with Stirling engines is not a new idea. The DoE sponsored SIPS program of the 1970's (13) produced a $1 \mathrm{kWe}$ unit, based on a kinematic engine driving a three phase alternator, which was carried to prototype performance testing. With a design requirement for 6 month service intervals, however, it was not a power source for long term remote missions. The more recently developed free-piston Stirling engine (FPSE) combined with a linear alternator (LA) shows more promise. Having been reduced to only those moving parts which are absolutely necessary to effect the Stirling cycle and generate electricity, this convertor (Fig. 5) not only retains the high thermal efficiency of its kinematic predecessor, but adds the potential for greatly extended life. With typically only two moving parts, it is mechanically simple. It can be hermetically sealed, with no oils or other organic materials inside to degrade or contaminate. Like the Brayton, the moving parts can be lubricated by the gas working fluid. No sliding or rotating seals of any kind are used; the moving parts are essentially not in contact. Since its vibrations are basically monochromatic (reciprocating parts 60 to $100 \mathrm{~Hz}$ ) they are relatively easy to attenuate or tune out.

Operated in reverse as a refrigerator, this machine has already seen use in space for reconnaissance and earth resources monitoring missions, providing cryogenic cooling for infrared imaging sensors (14).

Currently it is being developed for space power under the Civil Space Technology Initiative High Capacity Power program, by NASA as a multi-kWe convertor for nuclear reactor heat sources (15). The primary applications are stationary power plants for a lunar base, and nuclear electric propulsion for manned Mars missions. Goals of the program are to demonstrate a compact, high power density $(7 \mathrm{~kg} / \mathrm{kWe}$ ) convertor with maximum efficiency at temperature ratios applicable to space power, and continuous service life exceeding $60000 \mathrm{hr}$. During the course of this development program, thermal-to-electric conversion efficiencies better than 20 percent have already been demonstrated at temperature ratios as low as 2.2. This convertor represents a significant scale-up from the technology heritage of earlier machines which were $3 \mathrm{kWe}$ or less.

The FPSE differs from turbomachines in that it can be advantageously sealed into the multihundred-watt range of unit size and below. Published performance data from various units previously built and tested (16 to 21), plotted in Fig. 6, demonstrate consistent performance over a range of unit power output ( $5 \mathrm{~W}$ to $12.5 \mathrm{~kW}$ ) roughly four orders of magnitude. Data published by the CSTI engine contractor (22) indicates that a multihundred-watt FPSE/LA power module with conversion efficiencies of 25 to 35 percent should have a specific weight within the range 12 to $15 \mathrm{~kg} / \mathrm{kWe}$ at temperature ratios associated with dynamic isotope systems (2.2 and above). This supports the proposition that a multihundredwatt power module could produce a small Stirling DIPS that is competitive. Since the CSTI space power convertor was essentially an extension of the technology base from smaller FPSE units it is believed that a multihundredwatt space power unit could be brought to development rather rapidly, possibly within five years.

The key to small Stirling DIPS is thermal integration of the FPSE heater head with GPHS, the only space qualified heat source presently available. Approximately 250 thermal watts each, these modules are designed for radiative coupling to the conversion system. For a multikilo-watt DIPS, radiative coupling complicates thermal integration because there must be an insulated container (heat source assembly) which is separate from the convertor in order to hold the large number of GPHS modules, and a high temperature intermediate loop to collect and concentrate the heat. On the other hand, thermal integration of a multihundred-watt FPSE is relatively straightforward. The multihundred-watt FPSE needs a heat source consisting of only a few GPHS blocks. By clustering the blocks around the heater head as shown in Fig. 7, the FPSE heater head can be heated directly by radiative 
coupling. This eliminates the need for a separate insulated container and intermediate heat transfer loops. The blocks and heater head are enclosed within an integrated heat source/heater head assembly. Since every GPHS block must have an unobstructed view of the heater head, 750 We is about the largest unit that can be integrated in this fashion. Within this power range, however, direct integration significantly reduces size and weight.

A recent comparison of small Brayton and Stirling DIPS (major components, but without power conditioning or integration hardware) for distributed planet surface applications (23), illustrates the improvement in specific power that can be achieved when intermediate heat exchange and transport (insulated ducts, heat pipes, pumped loops) components are no longer needed (Fig. 8). In this comparison, the Brayton characterizations model the Rocketdyne DIPS-TECS GPHS heat souce assembly coupled to a single converter unit (turbomachinery, ducting and heat exchangers) optimized according to the Closed Cycle Engine Performance (CCEP) Code developed at NASA Lewis Research Center (24). Stirling characterizations, which were based on the CSTI convertor and small power module designs developed at NASA Lewis and the CSTI engine contractor, model a small freepiston Stirling engine $(20 \mathrm{~kg} / \mathrm{kWe})$ directly integrated with the GPHS heat source. Both systems assume a lightweight double-sided radiator. At $250 \mathrm{We}$, the weight savings of direct integration combined with Stirling's better performance yields almost double the specific power relative to the Brayton DIPS. Required radiator area is cut in half.

Recent design studies carried out at NASA Lewis and the University of Florida have established the feasibility and limits of direct integration through radiative coupling, and indicated the physical characteristics and performance that might be achievable by a small Stirling DIPS (25). A dual engine configuration (Fig. 9) was investigated. In these studies, various configurations of GPHS and insulation packages surrounding an opposed pair of FPSE heater heads were considered, depending on the output power level desired. Thermal modeling was performed to analyze the GPHS heat source and its integration into various (heat source/heater head) geometries using the analysis codes TRAYSYS and SINDA (26). GPHS thermal models were correlated with data supplied by General Electric's AstroSpace Division and DOE Mound Labs (two developers of GPHS). Heater head data was supplied by the NASA Lewis Stirling technology branch. The analysis confirmed feasibility of direct integration. For a heater head temperature of $1050 \mathrm{~K}$, the GPHS fuel clad could be maintained within safe operating limits under a variety of conditions including shutdown of one engine.

From the heat source/heater head geometries studied, a preliminary small Stirling dynamic isotope power system configuration emerged. Characterization of this concept, which included the heat source assembly, insulation package, convertor and downstream components, indicated that a multihundred-watt Stirling DIPS should have dimensions similar to the Mod RTG and exhibit a specific power of 7 to $10 \mathrm{We} / \mathrm{kG}$.

Results of the characterization are shown (240 and $480 \mathrm{We}$ ), with comparisons to GPHS RTGs and Mod RTGs, in Table 2. Since its size and weight appears competitive with Mod RTG for the power range, the greatly reduced fuel requirement of the small Stirling DIPS appears to extend the competitive range for dynamic conversion to power levels not previously considered.

There is also an incentive to consider this power source for Mars surface missions. Although Mars Rover studies generally assume that RTG's will be used to power the rover vehicle, neither the GPHS RTG nor its Mod RTG sucessor are capable of operating in that atmosphere. Both are designed to take advantage of the space environment in order to reduce weight to a minimum. Their internal cavities are vented to space, which provides vacuum for multifoil insulation and removes isotope decay products and outgas from the TE converter elements as they sublime at $1300 \mathrm{~K}$. The space vacuum maintains integrity of the TE elements. At full operating temperature, the presence of minute quantities of oxygen or $\mathrm{CO}_{2}$ would rapidly oxidize them. Since this vacuum is not available on Mars, modification of a 
space RTG for the rover mission will increase its mass. The SNAP 19a RTG powering the Viking landers (27) used a hermetically sealed container and cover gas, flooding the container cavity with mixture of argon and helium at $1 \mathrm{~atm}$ (the convertor was sealed against a hot junction temp of $820 \mathrm{~K}$ ). Solid insulation was used to reduce heat loss. As a strategy to avoid degradation it proved successful, but the generator was heavy. Specific power was $2.3 \mathrm{~W} / \mathrm{kg}$. Modifying a space RTG for Mars will also entail increased risk. Schock (28) has proposed modifying the Mod RTG by hermetically vacuum sealing the annular convertor cavity containing the multifoil insulation and TE elements, and enclosing the GPHS stack in a separately sealed container that is placed inside the annulus but allowed to communicate to the outside via a selective vent. Although on paper this design maintains the low weight of the space unit, it depends on the ability of its hermetic seal to maintain less than 10 to 3 torr at $1300 \mathrm{~K}$, without external pumping, for 7 to 10 years. This creates a single point failure that negates the redundancy advantage enjoyed by TE's in the space unit.

The FPSE, on the other hand, will be insensitive to the Martian atmosphere because it is hermetically sealed and the superalloys typically used are stable in $\mathrm{CO}_{2}$ at operating temperature. The GPHS module in this case can vent directly to the outside since the local $\mathrm{CO}_{2}$ concentration is less than what the module normally gives off during the post-encapsulation reduction process (29).

This evidence may be sufficient to put the small Stirling DIPS into consideration for the missions listed in Table 1. Consideration for missions is only a first step, however. To gain acceptance, small Stirling DIPS will have to demonstrate high reliability and long life. Specifically, the challenge will be to demonstrate a high power density Stirling engine with 20 year life, and reliability in service on the order of 0.99 . For any system with moving parts this is a major challenge, since it will inevitably be compared to RTG thermoelectric convertors which have accumulated years of flight experience. A convincing demonstration of reliability and life will be needed. The missions, which may last ten years or more, are for scientific purposes not technology demonstration.

There is some evidence that the FPSE may be capable of meeting this challenge. Early in the NASA CSTI program, endurance testing was carried out on the MTI Engineering Model engine (30), a $3 \mathrm{kWe}$ developmental convertor equipped with gas bearings which were pressurized by an external supply. The original goal was to demonstrate $10000 \mathrm{hr}$ endurance, but only $5500 \mathrm{hr}$ operation were accumulated before funding limitations curtailed the program. Despite numerous test cell ancillary failures (such as starting the engine before the bearing supply was turned on) this engine always started and ran without incident. Teardown of the engine afterwards revealed that no measureable wear had occurred; only minor scratches were observed which were attributed to the dry starts.

More convincing evidence of reliability has been achieved by the small sized units. In the US, FPSE's have been developed for the National Institute of Health as a power source for the artificial heart, which has been under development since 1967. Their design goal is a fully implantable unit that will operate for 10 years without intervention. Major components of the artificial heart engine have accumulated over 14 years (10 exp 9 cycles) of life testing. During the course of this program, one prototype engine has acumulated $36000 \mathrm{hr}$ continous operation without failure (31).

There is also evidence concerning reliability and long life operating in harsh remote environments. A series of Stirling engine generator sets were developed by the British Atomic Energy Agency (at Harwell) for remote marine applications in the late 1960's and early 1970 's as replacements for thermoelectric generators in order to save fuel. These were free-piston/linear alternator machines. A total of seven units were built. Two were used to power buoys in the North Sea. Together they accumulated more than $31000 \mathrm{hr}$ of service. The longest period of continuous unattended operation was 21 months. Another unit accumulated two consecutive one year periods of continuous unattended operation powering a lighthouse in Galway Bay, Ireland. 
These field test units were heated by propane. Experience showed the machines to be reliable. Failures that ocurred were due to burner malfunction and not the convertor (32). The developmental prototype, which was radioisotope heated, remained in the laboratory and ran continously for 13 years (33).

To develop a long life FPSE suitable for space missions, the challenge is to perfect the displacer and power piston bearings which maintain clearances between the moving parts. Convertor testing to date, which has focused on performance, has seen prototype engines run for hundreds of hours with no measureable wear, but upon disassembly there has always been some evidence of rubbing. Since lifelimiting wear mechanisms associated with intermittent rubbing are hard to quantify it is difficult to predict long term life without data from long term tests. On the other hand, if noncontacting bearing development can be demonstrated such that evidence of rubbing no longer appears, engine life can be more positively predicted by temperature/stress/ fatigue considerations rather than tribological considerations which are harder to extrapolate. One approach that guarantees non contact is the flexure bearing (a variant of the diaphragm) which positively locates the moving part within its clearance. Historically, use of flexures is associated with short piston travel which limits the engine power density achievable. Recent developments in flexure technology, however, have expanded those limits (allowing greater axial movement while restricting radial motion), permitting higher power densities to be achieved. A secondary benefit from implementing flexures in a high power density engine is that starting friction could be greatly reduced.

Reliability can only be established by test data, and test data can only be obtained by hardware experience. Before a small Stirling can be flown it will have to be extensively tested on the ground. This test program will require a great deal of accelerated component failure testing since the production quantities needed to develop a statistical data base for critical components are lacking, and the missions are longer in duration than the anticipated technology development programs to support them. Mission failures are not acceptable; there will be no post mortem data from field units available to identify and correct the hardware failures. It will therefore be necessary to anticipate failure modes, and develop detailed understanding of each failure mechanism to the extent that it can be quantitatively predicted, and demonstrated by experiment during the course of the development program. For the Stirling technologist this will be a serious challenge, but the benefit is an isotope power source that is greatly reduced in cost, enabling more mission capability from the resources available.

\section{CONCLUSION}

The most likely missions for radioisotope power sources in the forseeable future are long duration robotic missions. Power levels associated with these missions are multihundred-watt. Although these missions can be reliably powered by RTGs, the use of RTGs is costly because they require large amounts of isotope heat source which is hazardous, hard to obtain, and expensive. Because a dynamic system requires significantly less isotope to produce power, it could reduce the costs and possibly the risks to the mission. This dynamic system must be small enough, light enough, and reliable enough to replace the RTG.

It is possible to build a multihundred-watt DIPS by combining the GPHS heat sources with free-piston Stirling convertor technology currently being developed. A high power density space engine, which can be scaled down to multihundred-watt unit size, is directly integrated with GPHS through radiative coupling with the FPSE heater head. This avoids intermediate heat transfer devices and minimizes heat losses. Thermal analysis has shown the concept to be feasible, and preliminary system characterization shows it to be attractive. On a per electrical watt basis it is equivalent in size and weight to the Mod RTG, but less than a third the heat source is required.

If reliability and life of the small free-piston Stirling convertor can be demonstrated, small Stirling DIPS can provide a low cost alternative to RTG's for these missions. Because this 
technology appears to have the potential to meet the mission requirements, and because the potential cost savings is too attractive to ignore, efforts are now underway to develop the small Stirling DIPS, and bring the long-lived multihundred-watt space engine to fruition.

\section{REFERENCES}

1.) M. Shirbacheh, "The Proceedings of the Radioisotope Power Systems Requirements Workshop," Jet Propulsion Laboratory, Pasadena, CA June 1990.

2.) R. Hartmann, "Modular RTG Technology Status," Proc. 25th IECEC, Vol. 1, AIChE, 1990, pp. 235-238.

3.) E. Skrabek, "Performance of Radioisotope Thermoelectric Generators in Space", Proc. 7th Symposium on Space Nuclear Power Systems, Albuquerque NM, January 1990

4.) USDọE Office of Space/Defense Energy Projects, March 1991

5.) R. Englehart, "Mechanics of Space Nuclear Safety," Space Nuclear Power Systems, Vol. 2, Orbit Book Co., 1984, pp. 497-503.

6.) G. Bennett et al, "Development and Implementation of a Space Nuclear Safety Program," Space Nuclear Power Systems, Vol. 6, Orbit Book Co., 1987, pp. 59-92.

7.) S. Aftergood, "A Critical View of Space Nuclear Power," Space Nuclear Power Systems, Vol. 8, Orbit Book Co., 1988, pp. 39-44.

8.) R. Johnson and A. Stadnik, "Dynamic Isotope Power Systems (DIPS) for Space Exploration - Technical Information," Rockwell International Rocketdyne Division document BD 90-27, prepared for USDOE under Contract No. DE-AC0388NE-32129, Canoga Park, CA, May 1990

9.) F.X. Dobler, "Mini-BRU/BIPS 1300 W(e) Dynamic Power Conversion System Development, Executive Summary," AiResearch Division of Garrett Corporation NASA CR-159440, 1978.

10.) G. Bennett, J. Janzen, J. Lombardo and A. Mehner, "The Dynamic Isotope Power
System Technology Program," Proc. 23rd IECEC, Vol. 3, ASME, 1988, pp. 131-136.

11.) R. Brandewie, "Lockheed Missiles and Space Company BSTS PowerSystem Definition Study", Rev. 1, RI/RD86-188, Rocketdyne Div., Rockwell International Corporation, Canoga Park CA July 1 , 1986

12.) W.R. Determan, D. Chung, A. Stadnik and R.A. Johnson, "Low Power DIPS for Interplanetary Missions," Proc. 25th IECEC, Vol.1, AlChE, 1990, pp. 210-215.

13.) D. Lehrfeld and W.D. Richards, "Stirling Engine Power System Development and Test Results," Proc. 15th IECEC, Vol. 3, AIAA, 1980, pp. 1967-1970.

14.) C. Chan, E. Tward and W. Burt, "Overview of Cryocooler Technologies for Space Based Electronics and Sensors," Advances in Cryogenic Engineering, Vol. 35, Plenum, 1990, to be published.

15.) J. Dudenhoeffer, "Programmatic Status of NASA's CSTI High Capacity Power Stirling Space Power Converter Program," Proc. 25th IECEC, Vol. 1, AIChE, 1990, pp. 40-46, (NASA TM-103142).

16.) M.A. White, et al,"Fully Implantable Stirling Engine for Artificial Heart Power," Proc. 17th IECEC, Vol. 4, IEEE, 1982, pp. 1778-1783.

17.) D. Berchowitz, "The Development of a 1 kW Electrical Output Free Piston Stirling Engine Alternator Unit," Proc. 18th IECEC, Vol. 2, AlChE, 1983, pp. 897-901.

18.) R. Berggren and T. Moynihan, "Free Piston Stirling Engine Experimental Program: Part 1-Baseline Test Summary," ANL-CT-83-7 Part 1, Argonne National Labs, June 1983.

19.) J. Schreiber, S.M. Geng and G.V. Lorenz, "RE-1000 Free Piston Stirling Engine Sensitivity Test Results", NASA TM- 88846, 1986.

20.) N.W. Lane, D.M. Berchowitz, D. Shade and A. Karandikar, "Development of a High Frequency Stirling Engine-Powered 3 kW(e) Generator Set," Proc. 24th IECEC, Vol. 5, IEEE, 1989, pp. 2213-2218.

21.) J.E. Cairelli, S.M. Geng, and R.C. Skupinski, "Results from Baseline Tests of 
the SPRE I and Comparison with Code Model Predictions," Proc. 24th IECEC, Vol. 5, IEEE, 1989, pp. 2249-2256.

22.) G. Dochat and M. Dhar, "Free Piston Stirling Engine System Considerations for Various Space Power Applications," Proc. 8th Symposium on Space Nuclear Power Systems, Albuquerque NM, January 1991.

23.) D. Bents et al "Comparison of Dynamic Isotope Power Systems for Distributed Planetary Surface Applications," Proc. 8th Symposium on Space Nuclear Power Systems, Albuquerque NM, January 1991.

24.) J. Klann, "Analysis and Selection of Design Conditions for a Radioisotope Brayton-Cycle Space Powerplant," NASA TN D-4600, 1968.

25.) D. Bents, et al, "Design of Multihundredwatt DIPS for Robotic Space Missions," Proc. 26th IECEC, Boston MA, August 1991.

26.) T. McComas, "Thermal Analysis of 250 We GPHS/FPSE/Dynamic Isotope Power Source Employing Direct Heat Source Integration," Proc. 26th IECEC, Boston MA, August 1991.

27.) W.M. Brittain and E.A. Skrabek, "SNAP 19 RTG Performance Update for the
Pioneer and Viking Missions," Proc. 18th IECEC, Vol. 3, AIChE, 1983, pp. 10561061.

28.) A. Schock, et al "Mars Rover RTG Study," Fairchild Report FSC-ESD-217/89/449

Aug. 10, 1989 (Also, IAF Paper 89-270).

29.) E. Johnson, "Post Encapsulation Plutonia Reduction for Galileo Ulysses GPHS Modules; the Module Reduction and Monitoring Facility (MRMF), ${ }^{n}$ Proc. 8th Symposium on Space Nuclear Power Systems, Albuquerque NM, January 1991.

30.) J. Slaby, "Overview of the 1985 NASA Lewis Research Center SP-100 FreePiston Stirling Engine Activities," Proc. 20th IECEC, 1985, pp. 3.180-3.188.

31.) M.A. White, et al,"Miniature Stirling Engines for Artificial Heart Power", Proc. 18th IECEC, Orlando FL, August 1983.

32.) E. Cooke-Yarborough,"Small Stirling-Cycle Power Sources in Marine Applications," OCEANS 80 International Conference on Ocean Engineering.

33.) E. Cooke-Yarborough, Personal Communication dated 17 Sept. 1990. 
Table 1-Missions That Will Require Radioisotope Power Sources

\begin{tabular}{|c|c|c|c|c|}
\hline Mission & $\begin{array}{l}\text { Proposed } \\
\text { launch date }\end{array}$ & Classification & $\begin{array}{c}\text { Mission } \\
\text { duration, } \\
\text { years }\end{array}$ & $\begin{array}{c}\text { EOM } \\
\text { power level, } \\
\text { W }\end{array}$ \\
\hline Craf & 1995 & $\begin{array}{c}\text { Code S } \\
\text { strategic plan }\end{array}$ & 7.5 & 461 \\
\hline Cassini & 1996 & $\begin{array}{c}\text { Code S } \\
\text { strategic plan }\end{array}$ & 10.5 & 480 \\
\hline Pluto flyby & 1998 & $\begin{array}{l}\text { Solar system } \\
\text { exploration }\end{array}$ & 14 to 16 & 500 to 600 \\
\hline Solar probe & 2000 & $\begin{array}{c}\text { Code S } \\
\text { strategic plan }\end{array}$ & 8 & 500 \\
\hline $\begin{array}{l}\text { Mars rover } \\
\text { sample return }\end{array}$ & 2001 & SEI precursor & 4 & 500 \\
\hline $\begin{array}{l}\text { Comet nucleus } \\
\text { sample return }\end{array}$ & 2002 & $\begin{array}{l}\text { Solar system } \\
\text { exploration }\end{array}$ & 8 & 500 to 700 \\
\hline $\begin{array}{l}\text { Lunar site } \\
\text { survey rover }\end{array}$ & $\begin{array}{c}2002 \\
2006, \& 2010\end{array}$ & SEI precursor & 5 & 500 \\
\hline
\end{tabular}

\begin{tabular}{|c|c|c|c|c|}
\hline Mission & $\begin{array}{l}\text { Proposed } \\
\text { launch date }\end{array}$ & Classification & $\begin{array}{c}\text { Mission } \\
\text { duration, } \\
\text { years }\end{array}$ & $\begin{array}{c}\text { EOM } \\
\text { power level, } \\
\text { W }\end{array}$ \\
\hline $\begin{array}{l}\text { Nepturn orbiter } \\
\text { and landers }\end{array}$ & 2003 & $\begin{array}{c}\text { Solar system } \\
\text { exploration }\end{array}$ & 20 & 500 to 700 \\
\hline $\begin{array}{l}\text { Multiple asteroid } \\
\text { orbiter grand } \\
\text { tour (w/Landers) }\end{array}$ & 2005 & $\begin{array}{l}\text { Solar system } \\
\text { exploration }\end{array}$ & 10 to 12 & 500 to 700 \\
\hline $\begin{array}{l}\text { Mars site survey } \\
\text { rover }\end{array}$ & $\begin{array}{c}2005, \\
2007,2009, \\
2015, \& \\
2024\end{array}$ & SEI precursor & 5 & 400 \\
\hline $\begin{array}{l}\text { Jupiter grand } \\
\text { tour (Orbiter } \\
\text { and Landers) }\end{array}$ & 2006 & $\begin{array}{l}\text { Solar system } \\
\text { exploration }\end{array}$ & 10 to 12 & 500 to 700 \\
\hline Interstellar probe & circa 2010 & Space physics & 20 to 25 & 200 to 500 \\
\hline $\begin{array}{l}\text { Polar heliospheric } \\
\text { probe }\end{array}$ & post 2010 & Space physics & 35 & 200 to 500 \\
\hline
\end{tabular}

Table 2-

(a) $240 \mathrm{~W}$ system comparison

\begin{tabular}{|c|c|c|c|c|c|c|}
\hline & \multirow{2}{*}{$\begin{array}{c}\text { Power } \\
\text { source } \\
\text { mass, } \\
\mathrm{kg}\end{array}$} & \multicolumn{2}{|c|}{ Power source envelope } & \multirow{2}{*}{$\begin{array}{l}\text { Radiator } \\
\text { temperature }\end{array}$} & \multirow{2}{*}{$\begin{array}{l}\text { Number of } \\
\text { GPHS blocks } \\
\text { required }\end{array}$} & \multirow{2}{*}{$\begin{array}{c}\text { Isotope } \\
\text { fuel } \\
\text { required, } \\
\mathrm{kg}\end{array}$} \\
\hline & & $\begin{array}{c}\text { Diameter, } \\
\mathrm{cm}\end{array}$ & $\begin{array}{l}\text { Length, } \\
\mathrm{cm}\end{array}$ & & & \\
\hline GPHS-RTG & 45.3 & 42 & 110 & 540 & 18 & 8.1 \\
\hline MOD-RTG & 31.2 & 38 & 70 & 598 & 12 & 5.4 \\
\hline Small Stirling DIPS & 33.8 & 27 & 100 & 375 & 4 & 1.8 \\
\hline
\end{tabular}

(b) $480 \mathrm{~W}$ system comparison

\begin{tabular}{|l|l|l|l|l|r|r|}
\hline GPHS-RTG & 90.6 & 42 & 220 & 540 & 36 & 16.1 \\
MOD-RTG & 62.4 & 38 & 130 & 598 & 24 & 10.7 \\
Small Stirling DIPS & 59.8 & 27 & 120 & 375 & 8 & 3.6 \\
\hline
\end{tabular}




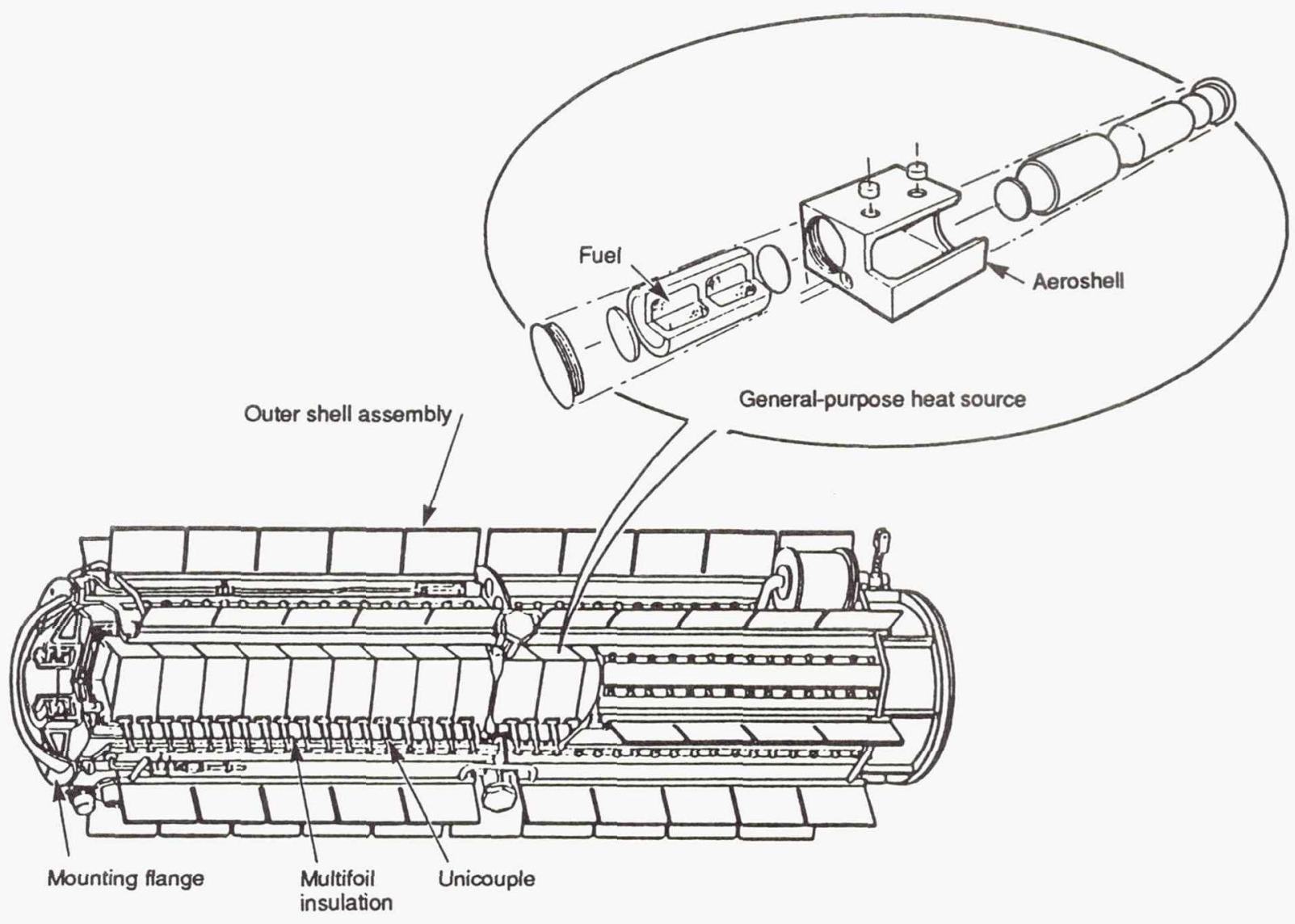

Figure 1.-General-purpose heat source-RTG.

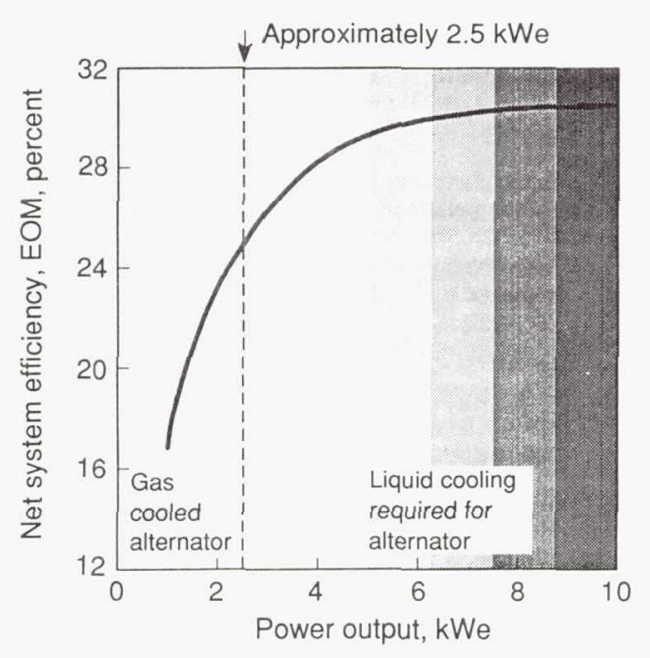

Figure 2.-DIPS efficiency characteristics; $1300 \mathrm{~K}$ turbine inlet temperature systems. Bearing, windage, thermal, electrical losses represent larger fraction at lower power. Smaller diameters decrease aerodynamic efficiencies at low power. (From Ref. 8.)

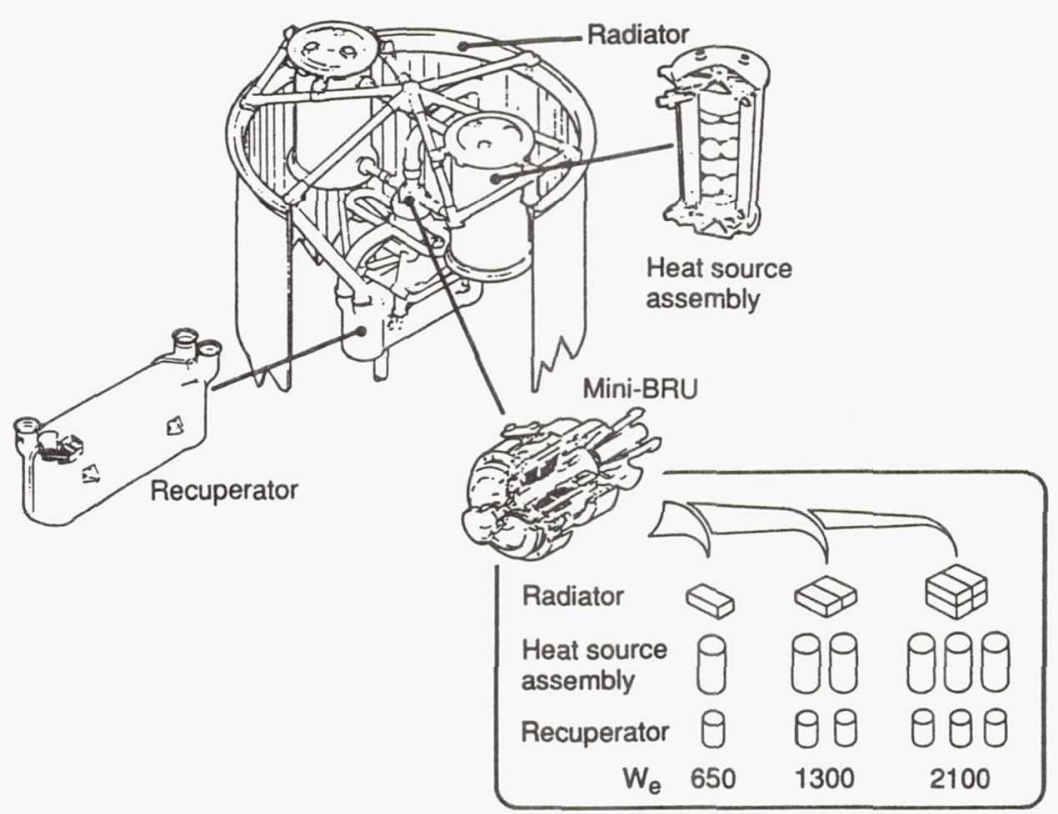

Figure 3.-Brayton isotope power system (BIPS). 


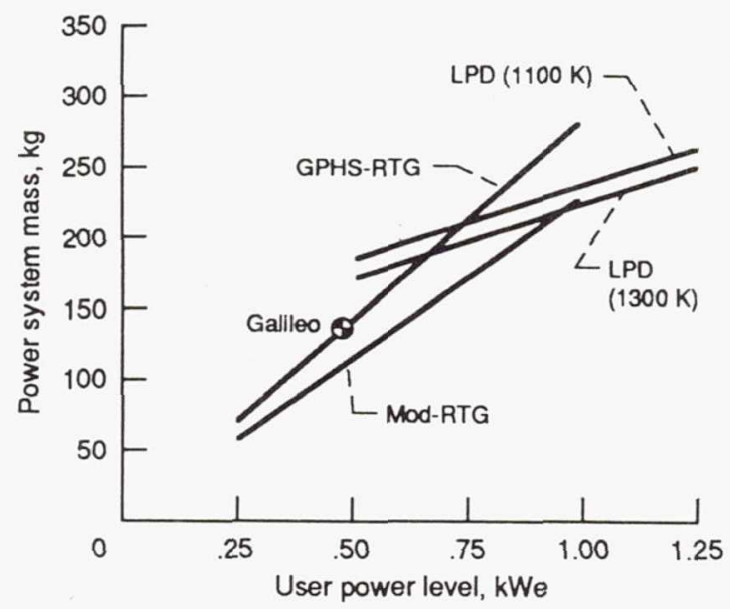

Figure 4.-Low-power DIPS versus RTG system masses (from ref. 12).

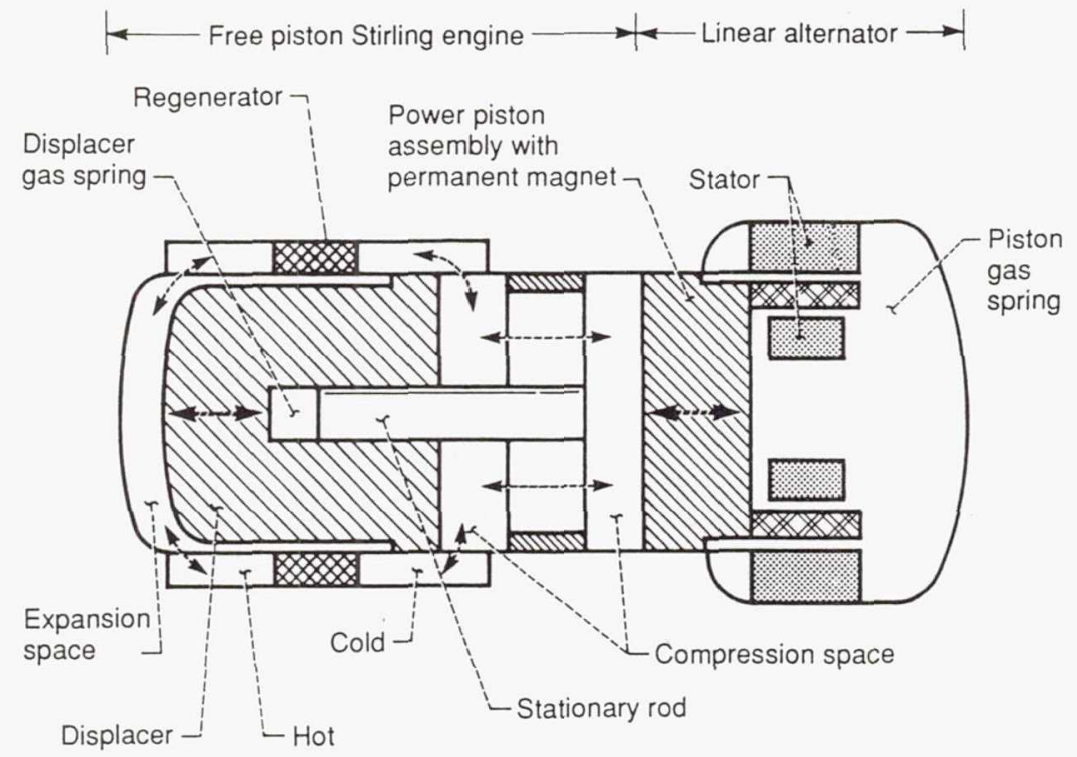

Figure 5.-Free piston Stirling engine/linear alternator. 


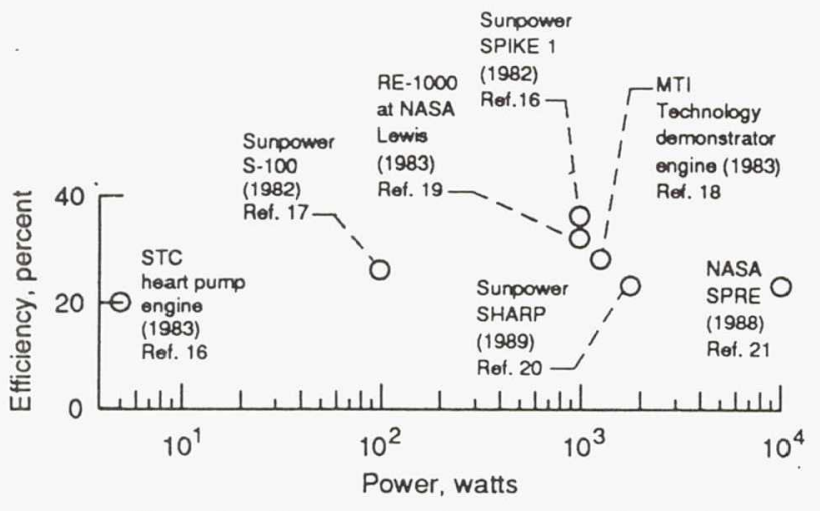

Figure 6.-Measured performance of selected free piston Stirling engines of various unit sizes.

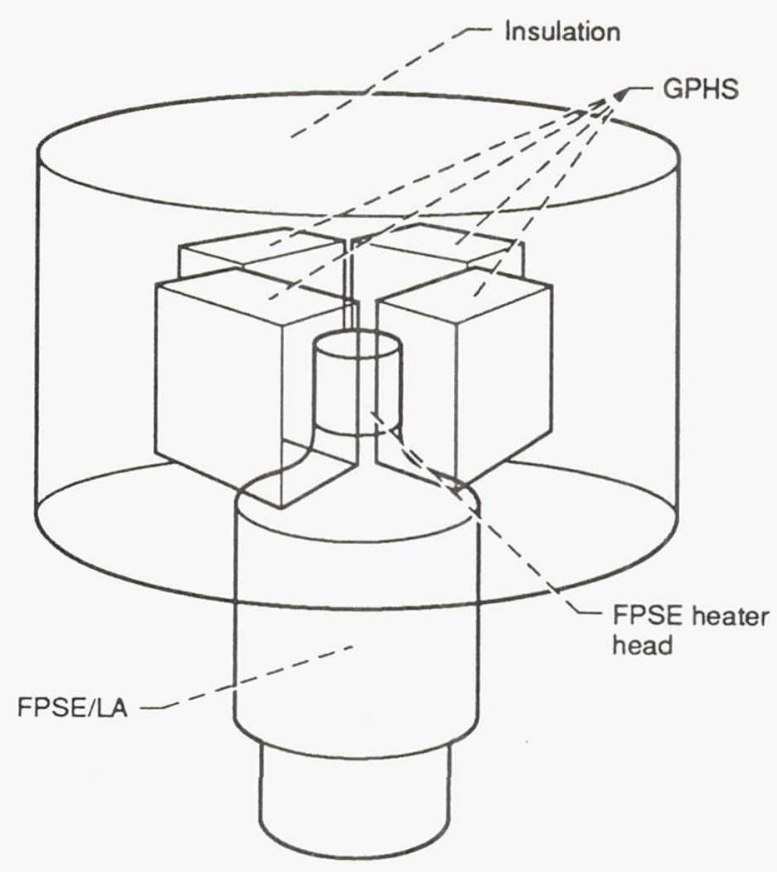

Figure 7.-Direct heat source/heater head integration.
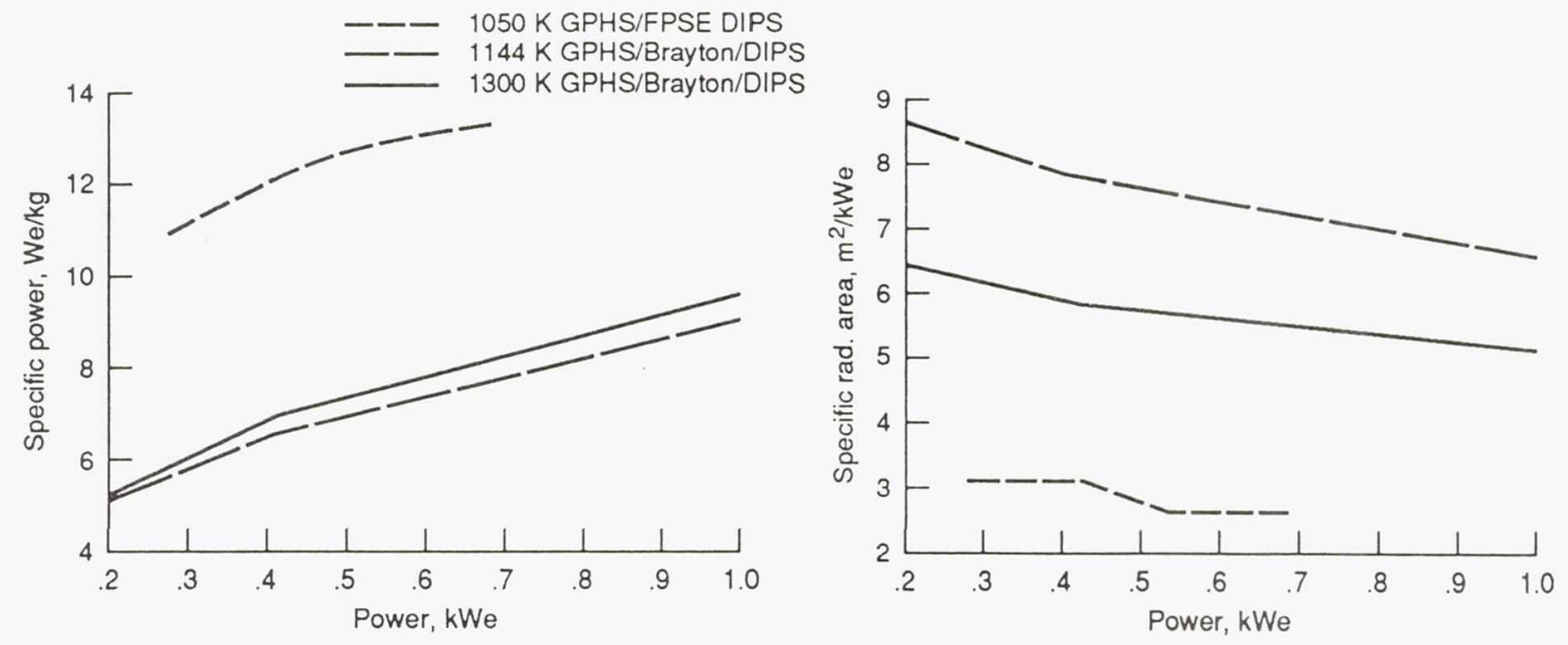

Figure 8.-Multihundred watt unit comparison. Stirling DIPS (direct integration) versus mass optimized Brayton DIPS (single PCU). (From Ref. 23) 


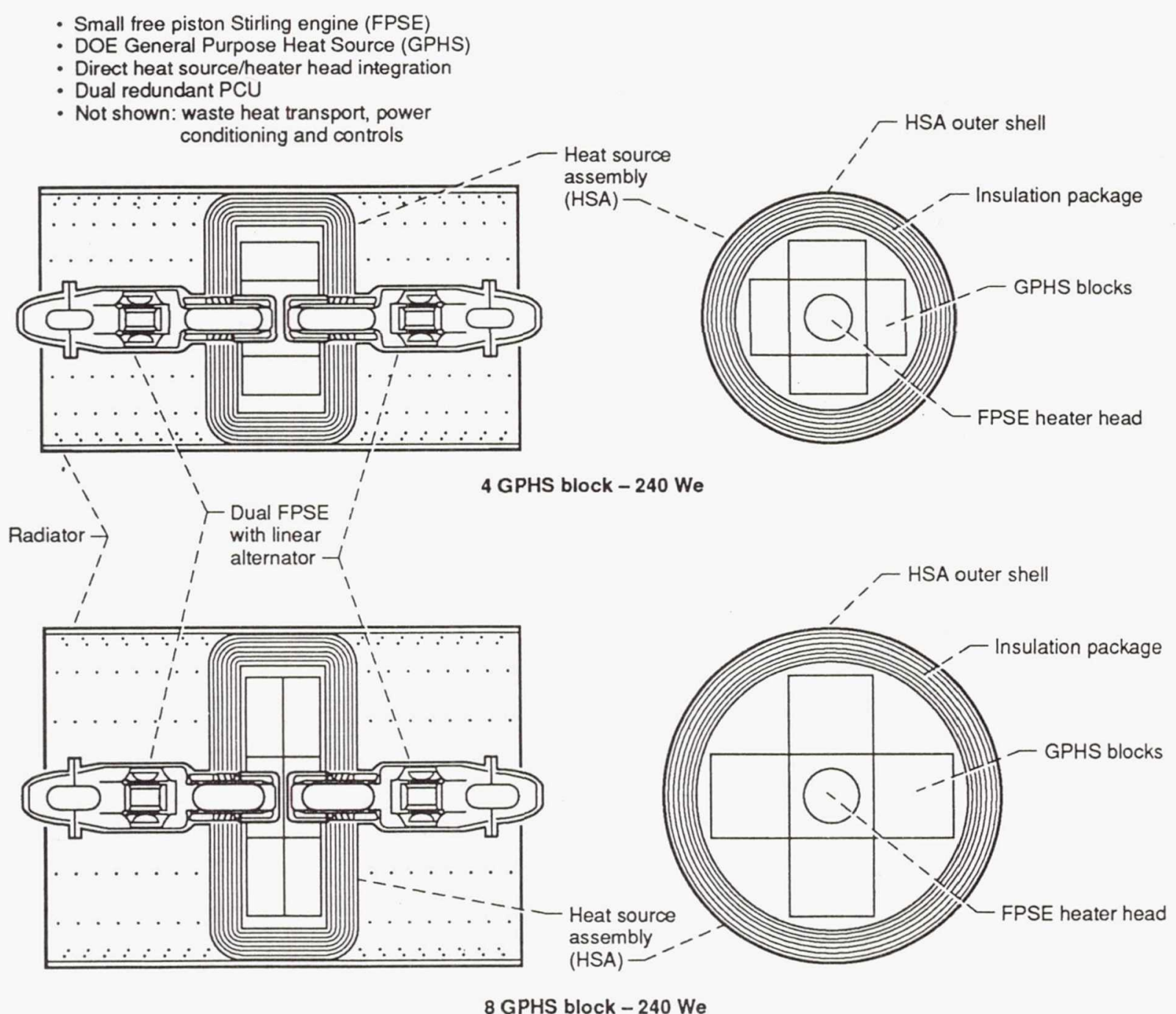

Figure 9.-Multihundred-watt GPHS/FPSE/DIPS. 


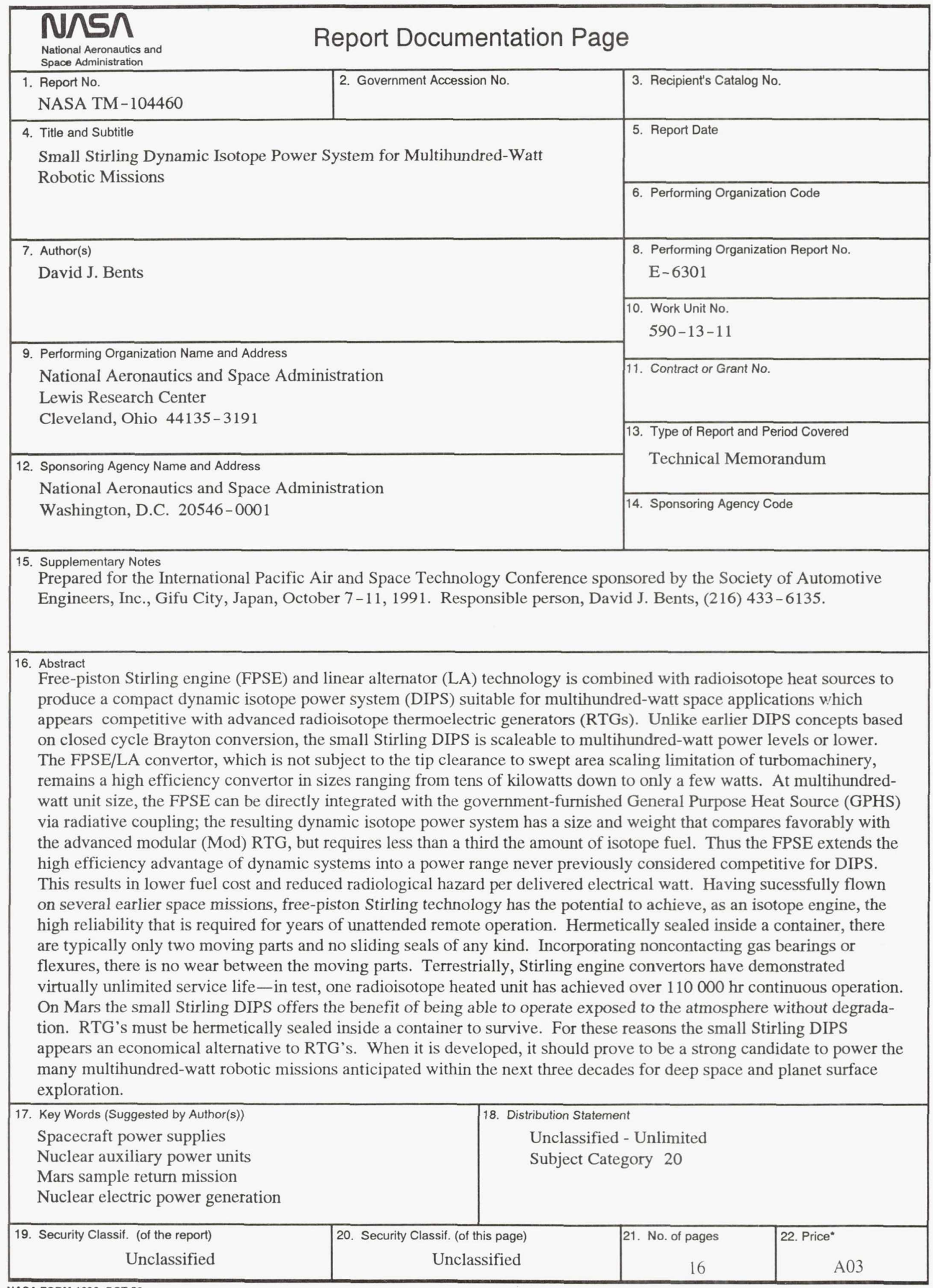

